\title{
Calpain Is a Major Cell Death Effector in Selective Striatal Degeneration Induced In Vivo by 3-Nitropropionate: Implications for Huntington's Disease
}

\author{
Nicolas Bizat, ${ }^{1}$ Jean-Michel Hermel, ${ }^{1}$ Frédéric Boyer, ${ }^{1}$ Carine Jacquard, ${ }^{1}$ Christophe Créminon, ${ }^{2}$ Stéphane Ouary, ${ }^{1}$ \\ Carole Escartin, ${ }^{1}$ Philippe Hantraye, ${ }^{1,3}$ Stan Krajewski, ${ }^{4}$ and Emmanuel Brouillet ${ }^{1}$ \\ ${ }^{1}$ Unité de Recherche Associée Commissariat à l'Energie Atomique (CEA)-Centre National de la Recherche Scientifique 2210, Service Hospitalier Frédéric \\ Joliot, Département de Recherche Médicale (DRM), Direction des Sciences du Vivant (DSV), CEA, 91401 Orsay, France, ${ }^{2}$ CEA, Service de Pharmacologie et \\ d'Immunologie, DRM, DSV, Centre d'Etudes Nucléaires Saclay, 91191 Gif sur Yvette, France, ${ }^{3} \mathrm{CEA}$, Isotopic Imaging, Biochemical and Pharmacology Unit, \\ Service Hospitalier Frédéric Joliot, DRM, DSV, CEA, 91401 Orsay, France, and ${ }^{4}$ Program on Cell Death and Apoptosis, The Burnham Institute, La Jolla, \\ California 92037
}

\begin{abstract}
Striatal cell death in Huntington's Disease (HD) may involve mitochondrial defects, NMDA-mediated excitotoxicity, and activation of death effector proteases such as caspases and calpain. However, the precise contribution of mitochondrial defects in the activation of these proteases in HD is unknown. Here, we addressed this question by studying the mechanism of striatal cell death in rat models of HD using the mitochondrial complex II inhibitor 3-nitropropionic acid (3-NP). The neurotoxin was either given by intraperitoneal injections (acute model) or over $5 \mathrm{~d}$ by constant systemic infusion using osmotic pumps (chronic model) to produce either transient or sustained mitochondrial deficits. Caspase- 9 activation preceded neurodegeneration in both cases. However, caspase- 8 and caspase- 3 were activated in the acute model, but not in the chronic model, showing that 3-NP does not require activation of these caspases to produce striatal degeneration. In contrast, activation of calpain was specifically detected in the striatum in both models and this was associated with a calpain-dependent cleavage of huntingtin. Finally, in the chronic model, which mimics a steady blockade of complex II activity reminiscent of HD, selective calpain inhibition prevented the abnormal calpain-dependent processing of huntingtin, reduced the size of the striatal lesions, and almost completely abolished the 3-NP-induced DNA fragmentation in striatal cells. The present results demonstrate that calpain is a predominant effector of striatal cell death associated with mitochondrial defects in vivo. This suggests that calpain may play an important role in HD pathogenesis and could be a potential therapeutic target to slow disease progression.
\end{abstract}

Key words: neurodegenerative disease; excitotoxicity; mitochondrial complex II inhibitor; calpain; caspase; calpain inhibitor; neuroprotection

\section{Introduction}

Huntington's disease (HD) is a genetic disorder associated with severe motor and cognitive deficits and preferential degeneration of medium spiny GABAergic neurons located in the striatum (Harper, 1991). Whereas the genetic defect responsible for HD is identified as an expansion of polyglutamine sequences within the huntingtin (Htt) protein (Huntington's Disease Collaborative Research Group, 1993), most of the pathological mechanisms linking the mutant protein to the selective neurodegeneration observed in the patient's brain remain highly speculative.

Mechanisms of cell death specifically implicated in HD pathogenesis include oxidative stress, mitochondrial defects, excitotoxicity, and activation of death effector proteases. The mitochondrial defects most consistently found in HD involve the succinate

Received Nov. 5, 2002; revised Feb. 27, 2003; accepted March 26, 2003.

This work was supported by Commissariat à l'Energie Atomique and (entre National de la Recherche Scientifique and National Institutes of Health Grant NS36821 (S.K.). We thank Drs. Kenneth L. Moya and Hirad Hedayat for comments and critical reading of this manuscript.

Correspondence should be addressed to Dr. Emmanuel Brouillet, Unité de Recherche Associée Commissariat à I'Energie Atomique (CEA)-Centre National de la Recherche Scientifique 2210, Service Hospitalier Frédéric Joliot, DRM, DSV, CEA, 4 place du Général Leclerc, 91401 Orsay CEDEX, France. E-mail: brouille@shfj.cea.fr. Copyright $\odot 2003$ Society for Neuroscience $\quad$ 0270-6474/03/235020-11\$15.00/0 dehydrogenase-complex II and $\mathrm{Ca}^{2+}$ homeostasis ( $\mathrm{Gu}$ et al., 1996; Browne et al., 1997; Tabrizi et al., 1999; Panov et al., 2002). Compelling evidence also supports the view that excitotoxic cell death plays a major role in HD (DiFiglia, 1990). This is further supported by more recent observations of transgenic mice overexpressing full-length mutated Htt in which striatal neurons display increased NMDA-evoked currents and are more vulnerable to the toxic effects of the NMDA-receptor agonist quinolinate (Cepeda et al., 2001; Laforet et al., 2001; Zeron et al., 2002). Finally, a central role in the toxicity of the mutant form of Htt of the proteases of the caspase family (Saudou et al., 1998; Sanchez et al., 1999; Wellington et al., 2002) and more recently of the $\mathrm{Ca}^{2+}$-activated neutral protease calpain (Kim et al., 2001; Gafni and Ellerby, 2002) has also been suggested. Despite this accumulating data, the precise contribution of these cell death mechanisms in HD pathogenesis is still unknown. A sequential process of cell death has been hypothesized for HD in which mitochondrial defects lead indirectly to excitotoxicity, activation of cell death effector proteases, and eventually cell demise (Albin and Greenamyre, 1992; Beal, 1992). An alternative mechanism proposes that all these steps are part of a self-amplifying vicious circle in which they are either initiated by, or themselves contribute to, 
an impairment of mitochondrial function leading to energy failure and ultimately cell death (for review, see Petersen et al., 1999). In support of the sequential process, experimental mitochondrial blockade using the selective complex II inhibitors malonate or 3-nitropropionic acid (3-NP) has shown that mitochondrial perturbation by itself can trigger NMDA receptor activation leading to selective degeneration of the striatal medium spiny GABAergic neurons (Brouillet et al., 1999). Whether the mitochondrial defects in HD mimicked by malonate and 3-NP are also directly responsible for the preferential activation of caspases and/or calpains in vivo is unknown.

To address this question, we used 3-NP-mediated succinate dehydrogenase $(\mathrm{SDH})$ inhibition in rats as a mean to produce either transient (acute model) or sustained (chronic model) mitochondrial deficits and characterized the pattern of caspase and calpain activation, in relation to these different patterns of mitochondrial perturbation. We found evidence for a regionally restricted calpain activation in both models in vivo. We then examined whether inhibiting calpain in vivo could also specifically protect the striatum in the chronic model of mitochondrial blockade.

\section{Materials and Methods}

Animals. We used 12-week-old male Lewis rats (Iffa Credo, L'Arbresle, France) weighing 340-370 gm. All experimental procedures were performed in strict accordance with the recommendations of the European Community (86/609/EEC) and the French National Committee $(87 / 848)$ for care and use of laboratory animals.

All chemicals and reagents were purchased from Sigma (L'Isle d'Abeau Chesnes, France) unless specified otherwise.

3-NP treatment and experimental design. Two different 3-NP-rat models were studied.

In the chronic model, a solution of 3-NP was delivered by chronic infusion $\left(54 \mathrm{mg} \cdot \mathrm{kg}^{-1} \cdot \mathrm{d}^{-1}\right)$ using osmotic minipumps (flow rate 10 $\mu \mathrm{l} / \mathrm{hr}$, model 2ML1; Alzet, Palo Alto, CA) placed subcutaneously in the back of the animals under ketamine-xylazine anesthesia (Dautry et al., 2000; Garcia et al., 2002; Mittoux et al., 2002; Blum et al., 2002). Control rats were sham-operated. In a first experiment, animals (5-6 per time point) were killed every $6 \mathrm{hr}$ from day 2 to day 5 for biochemical analysis (DNA fragmentation, caspase-3-related proteolytic activity, fodrin cleavage) and immunohistochemistry (caspase-3, -8, -9). In this experiment including 653 -NP-treated rats, survival was $100 \%$. In a second experiments in which animals were analyzed for activation of caspase-3, -8 and -9 and calpains by Western blot and proteolytic activity assays, groups of rats $(n=5-8)$ were killed by decapitation at daily intervals (days 1, 2, 3, 4, and 5) after osmotic pump implantation (day 0). In this experiment including 353 -NP-treated rats, one animal of the day 5 group $(n=7)$ died prematurely and could not be analyzed. All animals chronically treated with 3-NP were included in biochemical analysis.

In the acute model, animals received two intraperitoneal injections of $3-\mathrm{NP}(25 \mathrm{mg} / \mathrm{ml}, \mathrm{pH} 7.4,50 \mathrm{mg} / \mathrm{kg})$ at $90 \mathrm{~min}$ intervals. Control animals received intraperitoneal injections of saline. Animals were killed at 3, 6, 12,24 , and $48 \mathrm{hr}$ after the first intraperitoneal injection of the neurotoxin. Rats showed variable responses to this acute 3 -NP regimen. In the experiments presented, survival rate over the $48 \mathrm{hr}$ after injection was $87 \%$ (time point, $n$ survivor $/ n$ per group: $6 \mathrm{hr}, 7 / 7 ; 12 \mathrm{hr}, 7 / 7 ; 24 \mathrm{hr}, 8 / 10$; $48 \mathrm{hr}, 11 / 14)$. All rats of the $6 \mathrm{hr}$ group were used for analysis. For later time points, only rats with obvious uncoordination and/or dystonia among survivors were taken for analysis (time point, $n$ symptomatic/ $n$ survivors: $12 \mathrm{hr}, 7 / 7 ; 24 \mathrm{hr}, 5 / 8 ; 48 \mathrm{hr}, 10 / 11)$.

Calpain inhibitor I neuroprotection experiments in the chronic model. The calpain inhibitor I (CI-1; z-Leu-Leu-Norleucinal; Biomol, Plymouth Meeting, PA) solubilized in phosphate buffer saline containing $40 \%$ dimethylsulfoxide was delivered $(2.5 \mu \mathrm{g} / \mathrm{hr}, 1 \mu \mathrm{l} / \mathrm{hr})$ by intracerebroventricular infusion using an osmotic minipump (model 2001; Alzet) connected to a stereotaxically implanted cannula [anteroposterior (AP) -1.6 $\mathrm{mm}$, lateral $2.0 \mathrm{~mm}$ from bregma, ventral $3.5 \mathrm{~mm}$ from dura, using the "brain infusion kit"; Alzet]. The minipump delivering 3-NP and that delivering CI-1 were implanted simultaneously. Histological and biochemical evaluation was performed on day 5 of the neurotoxic treatment.

Brain processing, sample dissection, and homogenization. Brains were rapidly removed from the skull and cut vertically along the rostrocaudal axis into two hemispheres. The left hemisphere was fixed in Bouin's solution for $3 \mathrm{~d}$ and paraffin-embedded for immunohistochemical evaluation. For CI-1 studies, the left hemisphere was frozen in isopentane $\left(-30^{\circ} \mathrm{C}\right)$ and stored at $-80^{\circ} \mathrm{C}$ for histological evaluation. Striatum and cortex samples were dissected and processed for biochemical analyses from the right hemisphere. Tissue dissection was carried out on an icecooled platform. The lateral striatum and the surrounding cerebral cortex were dissected out from coronal slices (2-mm-thick) (Dautry et al., 2000). Tissue samples (10-20 mg) were homogenized using a $1 \mathrm{ml}$ glass Teflon potter ( $900 \mathrm{rpm}, 20$ strokes) in $300 \mu \mathrm{l}$ of ice-cooled buffer containing 25 mM HEPES-KOH, pH 7.4, 0.1\% Triton X-100, $5 \mathrm{~mm} \mathrm{MgCl}_{2}$, $1.3 \mathrm{~mm}$ EDTA, $1 \mathrm{~mm}$ EGTA, and proteases inhibitor cocktail (Roche, Meylan, France) (Namura et al., 1998). Homogenates were centrifuged at $15,000 \times g$ for $30 \mathrm{~min}$. The supernatant (soluble fraction) and the pellet (membrane fraction) were stored at $-80^{\circ} \mathrm{C}$ until analysis.

Western blot analysis. Protein concentrations were determined using the BCA method (Pierce, Rockford, IL) according to the manufacturer's instructions. Proteins in striatal and cortical fractions were separated by SDS-PAGE as previously described (Hermel et al., 1999). After blot transfer, nitrocellulose membranes were incubated overnight at $4^{\circ} \mathrm{C}$ with one of the antibodies raised against fodrin (1:2000, antibody against non-erythroid $\alpha$-spectrin; Chemicon, Temecula, CA), huntingtin [1:1000; 4C8 clone, antibody (Ab) 2166; Euromedex, Souffelweyersheim, France], caspase-9 (1:1000; Bur 81 and Bur 73, Krajewski et al., 1999), caspase-8 (1:1000; Bur 1890, Stoka et al., 2001), caspase-3 (1:1000; Ab 1797; Cell Signaling Technology, Beverly, MA) and $\mu$-calpain (1:1000; domain III, clone 9A4H8D3, Biomol). The blots were incubated with horseradish peroxidase-conjugated anti-mouse or anti-rabbit $\operatorname{IgG}$ (1:1000, Sigma), and peroxidase activity was detected using ECL reagent (Pierce).

Immunohistochemistry and histological studies. Caspase-9, -8, and -3 immunohistochemistry and Masson-trichrome staining was performed on paraffin sections as previously described (Krajewski et al., 1999; Stoka et al., 2001). The antibodies used for immunohistochemistry of caspases were similar to those used for Western blot. For neuroprotection studies, lesion severity was evaluated on frozen coronal sections ( $40-\mu \mathrm{m}$-thick). Cells with DNA fragmentation were detected by the terminal deoxynucleotidyl transferase-mediated biotinylated UTP nick end labeling (TUNEL) method using the "In situ cell death detection-fluorescein kit" (Roche) (Dautry et al., 2000; Ouary et al., 2000). For each animal, cells were counted over the entire surface of the striatum in one section at the same rostrocaudal level (AP $0.5 \mathrm{~mm})$ with a $20 \times$ objective ( $\cong 350$ fields of view per section) using an automated motorized stage and acquisition system (Fluovision; IMSTAR, Paris, France). SDH and cytochrome oxidase (COX) histochemistry was performed and quantitatively analyzed as previously described (Greene and Greenamyre, 1995; Brouillet et al., 1998).

Oligonucleosome detection. Oligonucleosome contents in soluble fractions $(20 \mu \mathrm{l})$ were determined using the "ELISA cell death detection kit" (Roche) according to the manufacturer instructions. The results were normalized by the protein concentrations in each sample and expressed as mean $\mathrm{OD}$ values $\pm \mathrm{SEM}$.

Proteolytic activity assay using fluorogenic substrate for caspases and calpain. The fluorescent assay of the protease activity is based on the cleavage of 7-amino-4-methyl-coumarin (AMC) or 7-amino-4-trifluoro-methylcoumarin (AFC) dyes from the $\mathrm{C}$ terminus of the peptide substrates. The calpain activity was determined using $N$-succinyl-Leu-Tyr-( $N$-succinylLY)-AMC, a substrate preferentially cleaved by $\mu / \mathrm{m}$-calpain (McDonald et al., 2001). Calpain activity $\left(\mathrm{Ca}^{2+}\right.$-dependent cleavage of $N$-succinylLY-AMC) present in brain sample supernatants $(\sim 10 \mu$ l containing $\sim 30$ $\mu \mathrm{g}$ of protein) was determined as the difference between the calciumdependent and the non-calcium-dependent fluorescence. The calciumdependent fluorescence released was measured after $30 \mathrm{~min}$ incubation at $37^{\circ} \mathrm{C}$ in buffer A containing $63 \mathrm{~mm}$ imidazol- $\mathrm{HCl}, \mathrm{pH} 7.3,10 \mathrm{~mm}$ 
$\beta$-mercaptoethanol, and $5 \mathrm{mM} \mathrm{CaCl}_{2}$ and is attributable to the cleavage of $150 \mu \mathrm{M} N$-succinyl-LY-AMC. The non-calcium-dependent fluorescence was measured under the same conditions using buffer A without calcium and containing $1 \mathrm{~mm}$ EDTA and $10 \mathrm{~mm}$ EGTA. To measure the inhibiting effects on calpain activity of striatal samples from animals treated in vivo with CI-1 or its vehicle, $10 \mu \mathrm{l}$ of supernatant was incubated in $90 \mu \mathrm{l}$ of calpain assay buffer containing purified $\mu$-calpain ( $0.2 \mathrm{U}$; Calbiochem). Caspase- $3,-8$, and -9 activities were tested on peptidic substrates (Biomol), using respectively $N$-acetyl-Asp-Glu-Val-Asp-AFC (DEVDAFC), $N$-acetyl-Ile-Glu-Thr-Asp-AFC (IETD-AFC), and $N$-acetyl-LeuGlu-His-Asp-AFC (LEHD-AFC). Soluble fractions (30 $\mu \mathrm{g}$ of protein) were incubated at $37^{\circ} \mathrm{C}$ for $45 \mathrm{~min}$ in a caspase buffer B (in mM: 20 HEPES, pH 7.4, $50 \mathrm{NaCl}, 0.2 \mathrm{EDTA}$, and 4 DTT) with $40 \mu \mathrm{M}$ of the appropriate substrate. The nonspecific activity was considered as the activity remaining in the presence of the fluorogenic substrate and $10 \mu \mathrm{M}$ of the appropriate caspase inhibitor i.e., the C-terminal aldehyde form (CHO) of the substrate (DEVD-CHO, IETD-CHO, and LEHD-CHO for caspase- $3,-8$, and -9 , respectively). Fluorescence (excitation/emission: $400 / 505 \mathrm{~nm}$ for AFC and 380/460 $\mathrm{nm}$ for AMC) was measured in 96 well plates using a "Fusion" fluorimeter (Packard Bioscience, Rungis, France). Enzyme activity was calculated using standard curves of AFC or AMC and expressed as mean activity (picomoles of AFC-AMC released per minute per milligram of protein) \pm SEM.

Calpain-induced cleavage of fodrin and huntingtin in vitro. The in vitro proteolysis of endogenous fodrin and huntingtin was studied after incubation $\left(1 \mathrm{hr}\right.$ at $\left.37^{\circ} \mathrm{C}\right)$ of control samples ( $20 \mu \mathrm{g}$ of protein) with purified $\mu$-calpain (0.2 U; Calbiochem) or recombinant caspase-3 (50 ng; Biomol) in $100 \mu \mathrm{l}$ of the assay buffer A or B, respectively. Digestion products were analyzed by SDS-PAGE $(8-20 \%$ gradient gel) followed by Western blot analysis.

Statistical analysis. Results were expressed as means \pm SEM. Statistical analysis included Student's $t$ test or one-way ANOVA followed by a post hoc Scheffé $F$ test.

\section{Results}

Time course of striatal degeneration and primary mitochondrial impairment in acute and chronic 3-NP models In the acute model, all 3-NP-treated rats showed symptoms of drowsiness, slowness of movement, and general uncoordination at $6 \mathrm{hr}$. Histological evaluation indicated that 43\% (3/7) of these animals had striatal lesions. Uncoordination and bradykinesia were more pronounced at $12 \mathrm{hr}$. At this time point, 71\% (5/7) of the animals showed tissue abnormalities, including shrinkage of medium neurons and edema in the striatum (data not shown). After $24-48 \mathrm{hr}$, symptomatic rats had developed severe and permanent dystonia of hindlimbs or recumbency. In these rats, the entire lateral striatum was lesioned with many cells displaying fragmented nuclei or condensed chromatin (Fig. $1 B, E$ ). Consistent with this, biochemical analysis showed evidence of nuclear damage in these animals with a significant 20-fold increase in free oligonucleosome levels (an index of DNA fragmentation) compared with control levels (Fig. 2). Thus in the acute model, the onset of striatal lesion was about $6 \mathrm{hr}$ after 3-NP injection and the bulk of degeneration occurred within $24 \mathrm{hr}$ of the $3-\mathrm{NP}$ administration.

In the chronic model, motor symptoms were prominent on day 4 in all treated rats and worsened on day 5 as previously described (Ouary et al., 2000; Garcia et al., 2002; Mittoux et al., 2002). Histological evaluation of the 3 -NP-treated animals $(n=6$ per time point) at day 3 , day 3 plus $6 \mathrm{hr}$, day 3 plus $12 \mathrm{hr}$, and day 3 plus $18 \mathrm{hr}$ did not show any striatal abnormalities. At day 4 , $37.5 \%(6 / 16)$ of the animals showed small lesions in the dorsolateral aspect of the striatum. This was associated with a sevenfold increase in free oligonucleosome levels compared with controls (Fig. 2). At day 4 plus $6 \mathrm{hr}$, day 4 plus $12 \mathrm{hr}$, day 4 plus $18 \mathrm{hr}$, and day 5 , all rats ( $n=6$ per group) showed striatal lesions. At day 5 ,

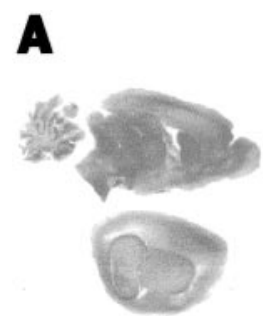

B

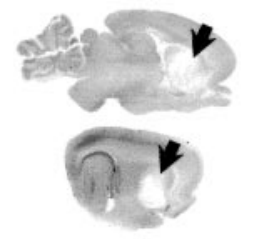

E

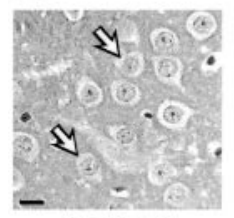

Control

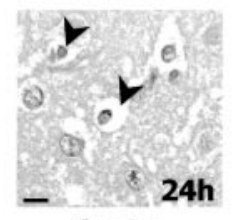

Acute

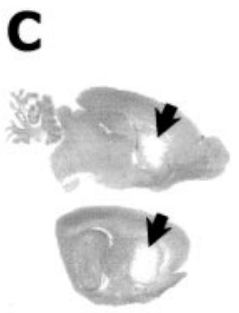

$\mathbf{F}$

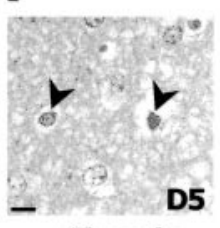

Chronic

\section{NP treated}

Figure 1. 3-NP-induced preferential degeneration and cell death in the striatum. Sagittal brain sections (Masson-trichrome staining) in control $(A, D)$, acute $(B, E)$, and chronic $(C, F)$ 3-NP models. $A-C$, Sections of the entire brain at low magnification at two different lateral levels showing the striatal lesion as a pale staining $(B, C$, arrows). $D-F$, High magnification of the striatum. Representative normal nuclear staining and the perikarya (devoid of staining, open arrow) of striatal cells (mainly projection neurons) in a control animal is shown in D. Abnormal chromatin condensation and cytoplasm reduction (arrowhead) in neurons is observed in the dorsolateral striatum at $24 \mathrm{hr}$ after acute 3 -NP injections $(E)$ and on day 5 in the chronic model (F). Scale bars, $10 \mu \mathrm{m}$.

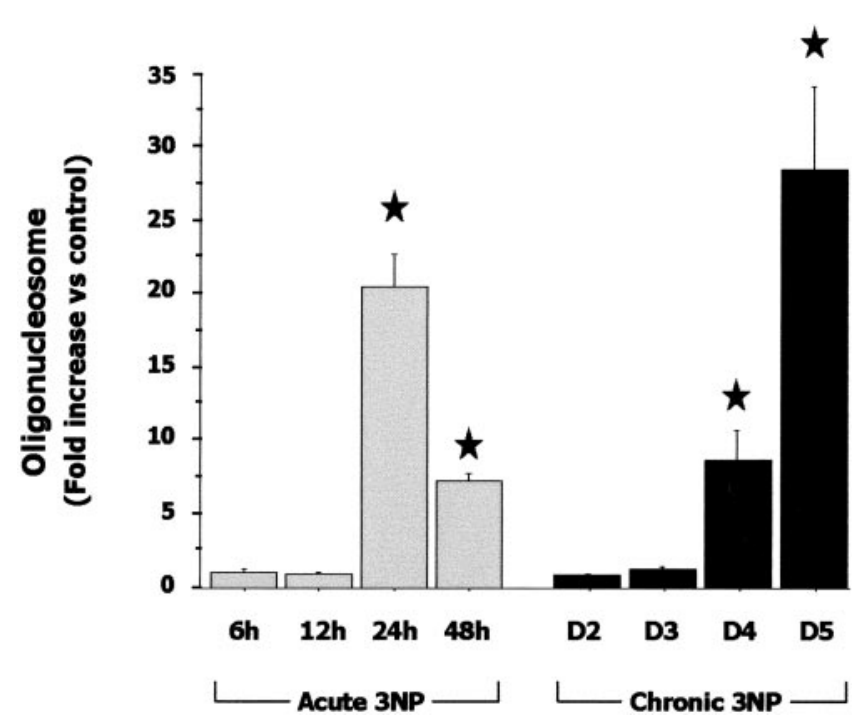

Figure 2. Evolution of nuclear DNA fragmentation in the striatum in the acute (open bars) and chronic (black bars) 3-NP models. What is shown is relative changes of free oligonucleosomes (i.e., an index of DNA fragmentation due to ongoing cell death) measured in the soluble fraction of striatal homogenates. Each bar corresponds to the mean value $\pm S E M$ determined in 6-10 animals. $\star p<0.0001$ compared with control, ANOVA, and post hoc Scheffé $F$ test.

the entire lateral part of the striatum was lesioned (Fig. 1C,F), and free oligonucleosome levels were increased 28-fold (Fig. 2). This shows that the onset of lesion was a few hours before day 4 , and aggravation of striatal cell death occurred within the next 24-30 hr. Thus, progression of obvious striatal cell death was relatively similar in both models.

The primary effect of 3-NP is the irreversible inhibition of the catalytic site of SDH, the main component of mitochondrial complex II (Brouillet et al., 1999). One important characteristic 


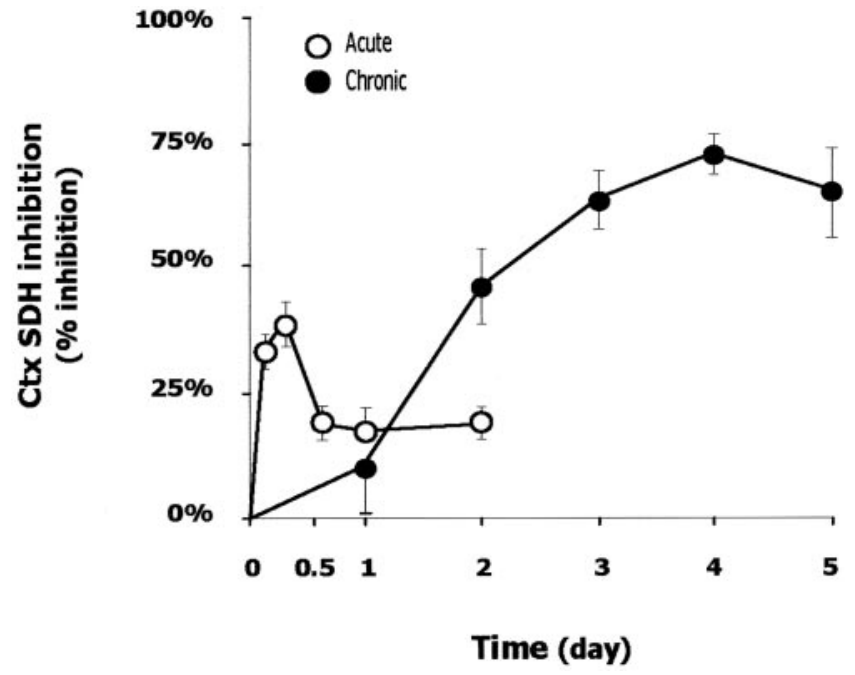

Figure 3. 3-NP-induced inhibition of cortical SDH activity in the acute and chronic models. In the chronic model, SDH inhibition reaches $\sim 65 \%$ on day 3 and remains constant thereafter. Note that in the acute model, SDH inhibition peaks at $6 \mathrm{hr}$ after injection of the neurotoxin and remains at low level thereafter. Each point corresponds to the mean value \pm SEM in six or seven animals. SDH inhibition was significant ( $p<0.01$ compared with control, ANOVA, and posthoc Scheffé $F$ test) at all time points considered.

of the 3-NP lesion model of HD is that although 3-NP inhibits striatal and extrastriatal (i.e., cerebral cortex) SDH activity to similar extent, the toxin produces a striatal degeneration with sparing of the cerebral cortex. Thus, region-selective neurodegeneration is not associated with a given levels of SDH inhibition in the brain (Brouillet et al., 1998; Garcia et al., 2002). Therefore, the loss of SDH activity in the cortex reflects solely 3-NP-induced inhibition of SDH, whereas in the striatum it reflects 3-NP blockade plus the loss of SDH containing neurons (Brouillet et al., 1998; Garcia et al., 2002). To estimate the levels of SDH inhibition in the striatum caused solely by 3-NP-induced blockade of the enzyme, we measured SDH activity in the cortex.

In the acute model, cortical SDH activity was inhibited by $40 \%$ after 3-6 hr (Fig. 3). This SDH inhibition decreased at $12 \mathrm{hr}$ so that SDH activity was at $80 \%$ of control and remained at this level up to $48 \mathrm{hr}$ after 3 -NP injection. These data show that in an acute experimental paradigm, 3-NP produces a "transient" peak effect on oxidative energy metabolism (Fig. 3).

In marked contrast, in the chronic model, $\mathrm{SDH}$ activity was progressively inhibited, decreasing by $60-70 \%$ on days $3-5$ (Fig. 3 ). These data indicate that very different patterns of SDH inhibition can be achieved depending on the systemic administration of the mitochondrial toxin and that only the chronic model is associated with a sustained $60-70 \%$ inhibition of complex II reminiscent of that seen in HD.

Differential patterns of caspase activation are found in acute and chronic models of mitochondrial blockade

After acute administration of 3-NP, in the striatum, caspase-9related LEHDase activity (Fig. $4 A$ ) showed a significant increase at $12 \mathrm{hr}$ compared with controls, and Western blot analysis showed accumulation of the processed p34 subunit of caspase- 9 (Fig. 4B). Consistent with this finding, immunohistochemistry of active caspase-9 showed labeled cells in the striatum (Fig. 4C). Caspase-8-related IETDase activity (Fig. 5A) was also significantly increased at $12 \mathrm{hr}$, and an increase in the processing of caspase- 8 was observed by Western blot (Fig. $5 B$ ) and immuno-
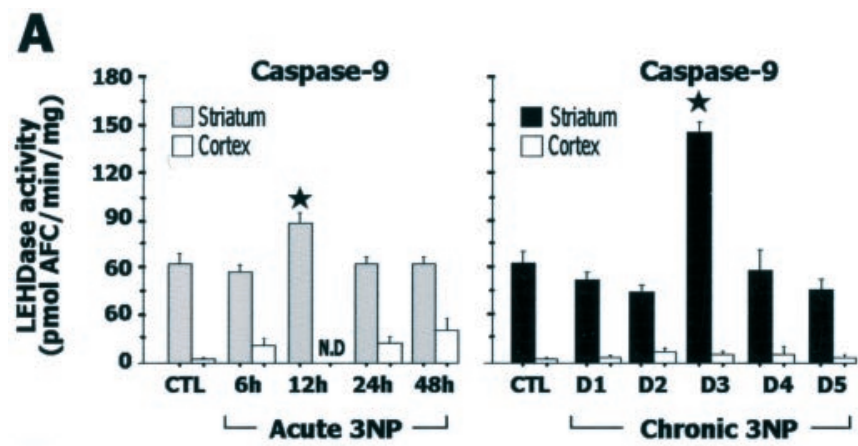

B
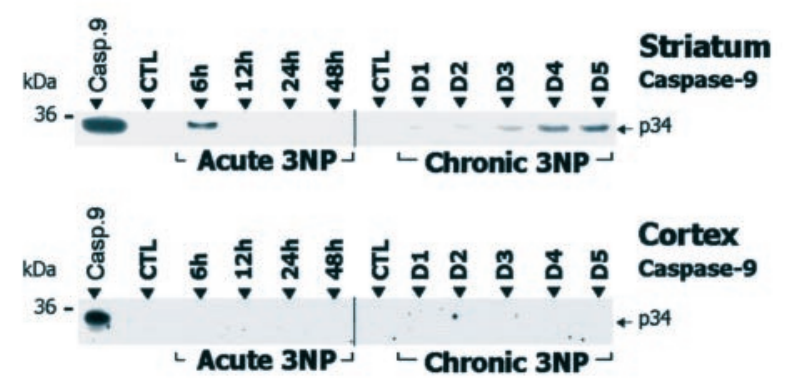

C

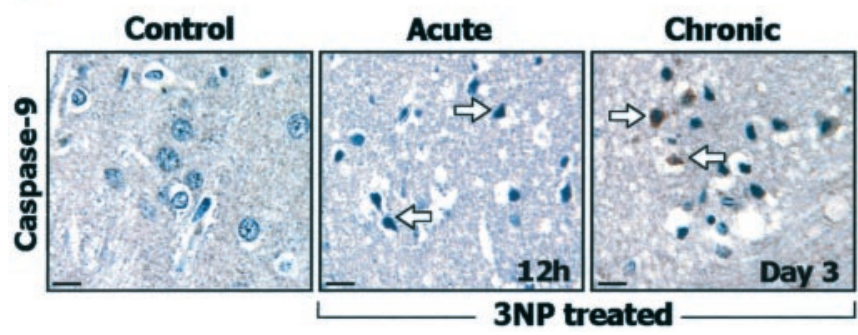

Figure 4. Study of caspase-9 in rats after acute or chronic 3-NP treatment. A, Caspase-9related LEHDase proteolytic activity in cerebral cortex and striatum. $B$, Analysis of striatal and cortical samples by SDS-PAGE followed by Western blot for the active form of caspase- 9 . Recombinant caspase-9 (Casp.9) was loaded in the left lane as a positive control. Note that accumulation of the $p 34$ subunit of the active form of caspase- 9 is detected in the striatum in the acute and chronic 3-NP models. C, Immunohistochemistry of active caspase-9 showing low levels of immunoreactivity in the striatum of control rats, whereas a marked increased labeling (arrows) is detected in the acute model at $12 \mathrm{hr}$ and in the chronic model at day 3. Data are means \pm SEM determined in 5-10 animals. N.D., Not detectable. $\star p<0.001$ compared with control, ANOVA, and post hoc Scheffé $F$ test.

histochemistry (Fig. 5C). In the same animals, significant increase in striatal caspase-3-related DEVDase proteolytic activity was detected at $24 \mathrm{hr}$ (Fig. 6A). The presence of processed caspase- 3 in the striatum was also demonstrated by Western blot analysis for the active form p17/19 (Fig. 6B). Accumulation of the processed form of caspase- 3 in degenerating striatal cells was detected by immunohistochemistry at 12 and $24 \mathrm{hr}$ (Fig. 6C). In summary, the acute model was associated with increased processing of both initiator and effector caspases.

During chronic 3-NP administration, a transient increase in caspase-9-related LEHDase proteolytic activity was detected within the striatum at day 3 (Fig. $4 A$ ). Western blot and immunohistochemical analysis of the active form of caspase- 9 also showed an accumulation of the processed form of caspase-9 (Fig. $4 B, C)$. Caspase-8-related IETDase activity was not increased in the chronic model (Fig. 5A). Consistent with this, Western blot analysis and immunohistochemistry showed no detectable accumulation of the active caspase- 8 subunit p20 (Fig. 5B,D). Simi- 


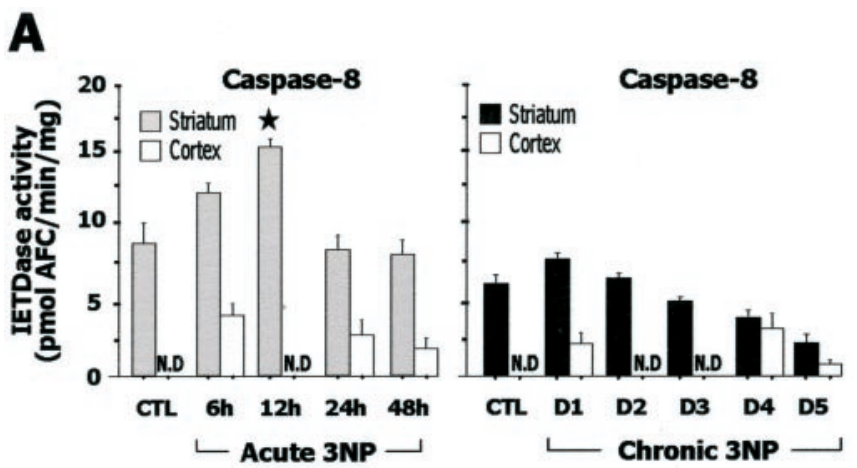

B
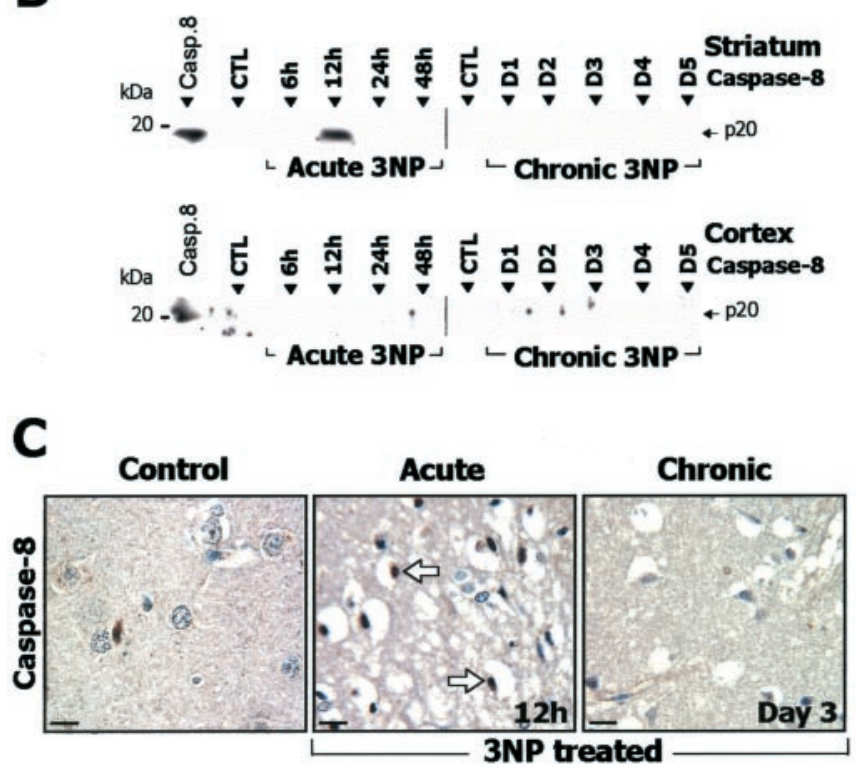

Figure 5. Study of caspase-8 in rats after acute or chronic 3-NP treatment. A, Caspase-8related IETDase proteolytic activity in striatal and cortical homogenates. $B$, Analysis of brain samples by SDS-PAGE followed by Western blot for the active form of caspase-8. Recombinant caspase-8 (Casp.8) was loaded in the left lane as a positive control. Note that accumulation of the p20 subunit of the active form of caspase-8 is detected only in the striatum in the acute 3-NP model at $12 \mathrm{hr}$. Ten micrograms of proteins were loaded per lane. C, Immunohistochemical analysis of caspases-8 showing low levels of immunoreactivity in the striatum in control and chronic model, whereas increased striatal labeling is observed in the acute model (arrows). Data are means \pm SEM determined in 5-10 animals. N.D., Not detectable. $\star p<0.02$ compared with control, ANOVA, and post hoc Scheffé $F$ test.

larly, there was no significant increase in caspase-3-related DEVDase activity in the same animals (Fig. 6A) or evidence of increased caspase- 3 processing as seen by Western blot analysis using an antibody selective for the p17/19 subunits of active caspase-3 (Fig. 6C). This absence of increase in DEVDase activity was observed in three independent experiments. To detect a possible transient activation of caspase- 3 in the chronic model, a group of rats was analyzed every $6 \mathrm{hr}$ from day 2 to day 5 . Again, we found no change in DEVDase activity compared with control in this group. Immunohistochemical evaluation of active caspase-3 in these animals showed only a few scattered immunoreactive neurons in the striatum at day 4 (Fig. 6C).

Interestingly, in the cerebral cortex, which is not sensitive to 3-NP toxicity but in which SDH is similarly inhibited as in the striatum, the same acute and chronic 3-NP rats showed no significant change in DEVDase, LEHDase, and IETDase activity (Fig. 4-6A). Consistently, Western blot analysis showed no
A

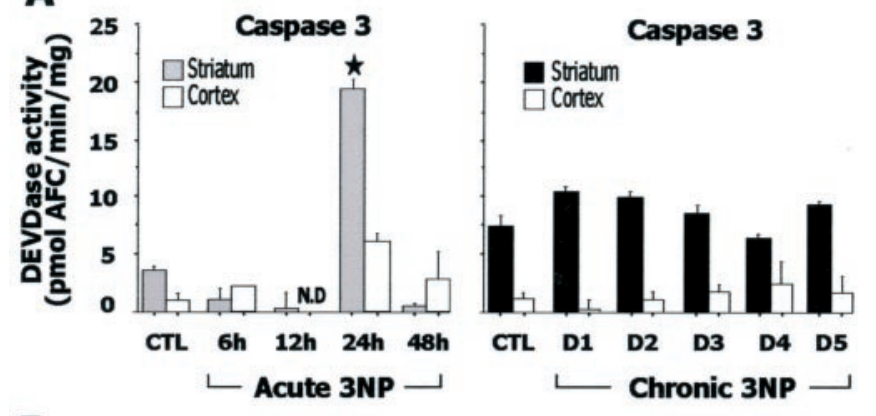

B

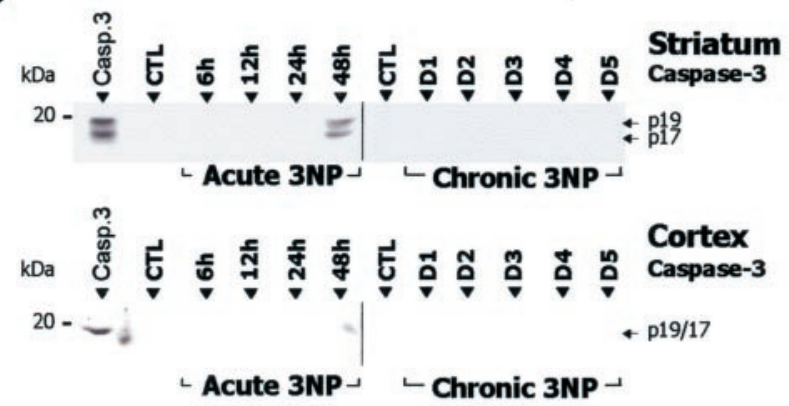

C

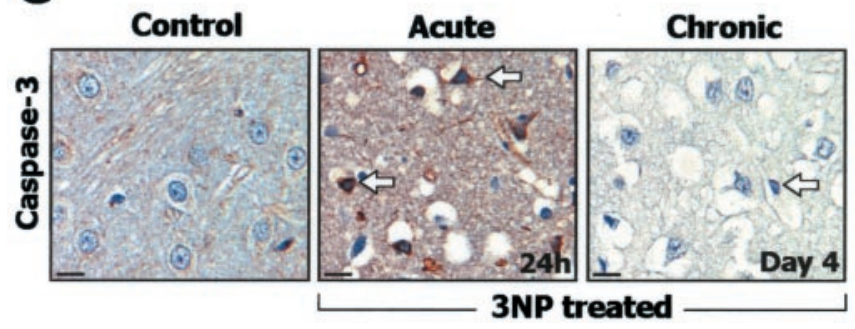

Figure 6. Study of caspase-3 in rats after acute or chronic 3-NP treatment. A, Caspase-3related DEVDase proteolytic activity in striatal and cortical homogenates. $B$, Analysis by SDSPAGE followed by Western blot for the active form of caspase-3. Recombinant caspase-3 (Casp.3) was loaded in the left lane as a positive control. Note that accumulation of the p20 subunit of the active form of caspase-3 (seen as a $17 / 19 \mathrm{kDa}$ doublet) is detected only in the acute 3-NP model at $48 \mathrm{hr}$. Ten micrograms of protein were loaded per lane. C, Immunohistochemical analysis of activated caspases-3 showing low levels of immunoreactivity in the striatum in control and chronic model, whereas marked increased striatal labeling in detected in the acute model (arrows). N.D., Not detectable. Data are means \pm SEM determined in 5-10 animals. $\star p<0.0001$ compared with control, ANOVA, and post hoc Scheffé $F$ test.

bands corresponding to active caspase- $9,-8$, and -3 in the cerebral cortex of 3-NP-treated rats (Fig. 4-6B).

3-NP-induced mitochondrial complex II defect is associated with calpain activation

To further characterize the mechanism of cell death involved in striatal degeneration associated with complex II defect in vivo, we studied the pattern of cleavage of fodrin (non-erythroid $\alpha$-spectrin) in the two models of mitochondrial defects. Fodrin is a known substrate of caspase- 3 as well as of the calcium-activated neutral proteases, $\mu$ - and $\mathrm{m}$-calpain (Wang, 2000). Importantly, caspase-3-mediated cleavage of fodrin leads to 150 and $120 \mathrm{kDa}$ breakdown products, whereas calpain-mediated cleavage results in a doublet near $145 / 150 \mathrm{kDa}$ (Wang, 2000). In the acute model, a specific calpain-dependent cleavage of fodrin leading to accumulation of the $145 / 150 \mathrm{kDa}$ products was detected at $12 \mathrm{hr}$ in the striatum (Fig. 7A). The intensity of the $145 / 150 \mathrm{kDa}$ doublet 
A
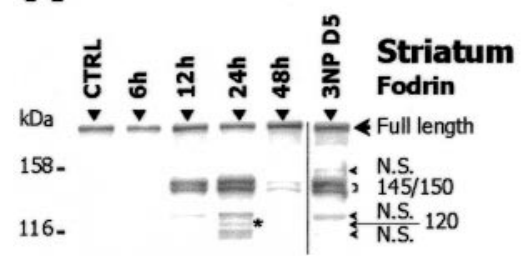

L Acute 3NP $\lrcorner$

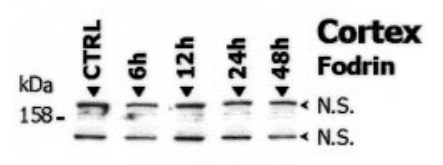

$\llcorner$ Acute 3NP $\lrcorner$

D

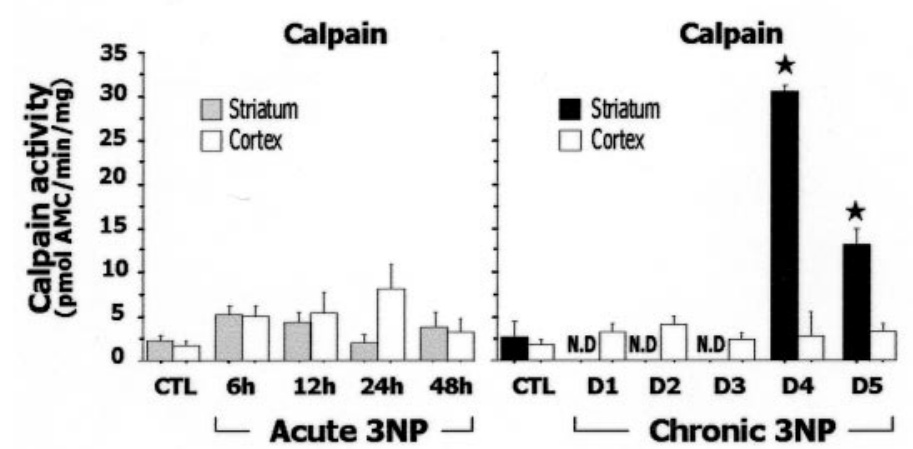

B
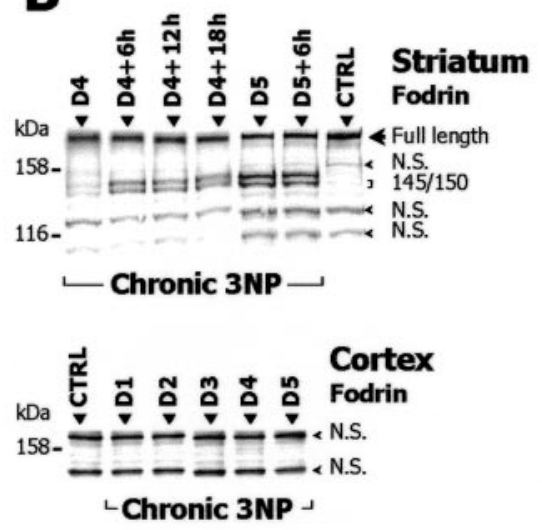

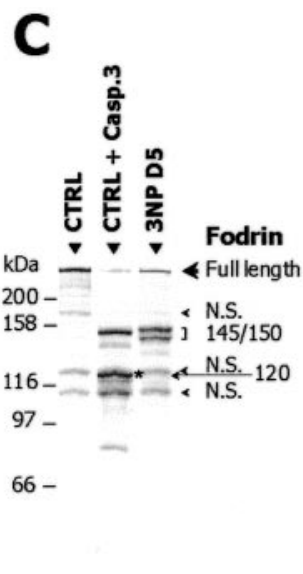

E

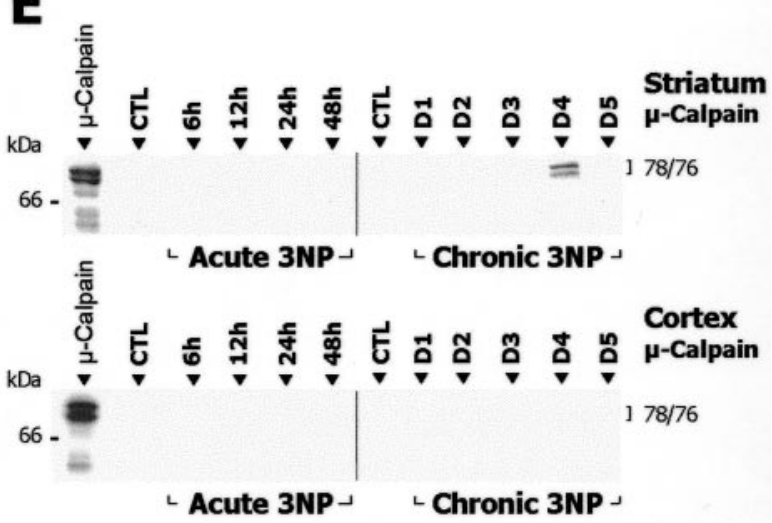

Figure 7. Calpain activation in acute and chronic 3-NP models. A-C, Homogenates prepared from striatum and cerebral cortex of 3-NP-treated and control (CTRL) rats were analyzed by SDS-PAGE followed by Western blot for fodrin (known substrate of calpain and caspase-3) and assayed for calpain-dependent proteolytic activity using the fluorogenic substrate N-succinyl-LY-AMC (D). $E$, Western blot analysis of $\mu$-calpain cleavage in cytosol fractions from striatum and cerebral cortex of 3-NP-treated animals. The typical calpain-dependent cleavage of fodrin appearing as a $145 / 150$ $\mathrm{kDa}$ doublet is found in the striatum of both acute $(A)$ and chronic $(B) 3-N P$ models (each lane contains pooled samples from $5-8$ animals). Note in $A$ the presence between two nonspecific (N.S.) bands of a $120 \mathrm{kDa}$ band (asterisk), possibly because of a caspase-3-mediated fodrin breakdown product. In $B$, chronic 3-NP animals were analyzed every $6 \mathrm{hr}$ showing that the intensity of this doublet increases on day 4 and is maximal at day 5 . Western blots for fodrin in cerebral cortex were slightly overexposed. C shows that the pattern found in the striatum of 3-NP-treated animals (day 5) is clearly different from the caspase-3-mediated cleavage of fodrin observed after in vitro digestion of control samples with recombinant caspase-3 (CTRL + R. Casp-3). Note the prominent increase in the proteolytic activity of calpain and the presence of cleaved/active form of $\mu$-calpain in the striatum of chronic 3-NP rats, whereas no changes were found within the cerebral cortex of the same animals. Data are means \pm SEM determined in 5-10 animals. N.D., Not detectable. $\star p<0.0005$ compared with control, ANOVA, and post hoc Scheffé $F$ test.

further increased at $24 \mathrm{hr}$, then disappeared at $48 \mathrm{hr}$. There was also a low concentration of the $120 \mathrm{kDa}$ breakdown product, possibly because of caspase-3-mediated cleavage (Fig. 7A).

Chronic 3-NP intoxication resulted in a specific calpaindependent cleavage of fodrin in the striatum and not in the cerebral cortex (Fig. $7 B, C$ ). This was evident as a progressive and selective accumulation of the $145 / 150 \mathrm{kDa}$ fodrin breakdown products on day 4. Accumulation was maximal at day 5 (Fig. $7 A, B)$. No caspase-3-mediated $120 \mathrm{kDa}$ breakdown product was observed at this time point (Fig. 7C).

To assess the proteolytic activity of calpain in striatum and cerebral cortex more directly, we measured the $\mathrm{Ca}^{2+}$-dependent cleavage of $\mathrm{N}$-succinyl-LY-AMC, a fluorogenic substrate cleaved by calpain, in both models. In the acute model, contrary to Western blot results above, we did not detect any increase in calpain activity at 6, 12, 24, and $48 \mathrm{hr}$ (Fig. 7D). This apparent discrepancy might be explained by a short-lived activation of this enzyme between 6 and $12 \mathrm{hr}$, leading to the accumulation of calpain-mediated breakdown products of fodrin detected in the striatum at 12 and $24 \mathrm{hr}$. In the chronic model, calpain activity was prominently increased i.e., 7 - to 10 -fold, at days 4 and 5 (Fig. $7 D)$ in the striatum, consistent with the accumulation of the fodrin $145 / 150 \mathrm{kDa}$ doublet.
We analyzed the expression and potential cleavage of $\mu$-calpain by Western blot. In the chronic model, we found an intense $76 / 78 \mathrm{kDa}$ doublet corresponding to the cleaved/active form of $\mu$-calpain at day 4 (Fig. $7 E$ ). Using the same Western blot conditions, this cleaved form of $\mu$-calpain was not found in the striatum in the acute model (Fig. $7 E$ ), consistent with a probable short-lived activation of the protease in this model.

Taken together, these results indicate pathological activation of calpains (including $\mu$-calpain) in the acute and chronic 3-NP models. Interestingly, this activation was specific to the striatum: no increased calpain proteolytic activity (Fig. 7D), no cleavage of $\mu$-calpain (Fig. $7 E$ ), and no modification of fodrin cleavage (Fig. $7 A, B)$ were detected in the cerebral cortex.

Because the chronic model was capable of reproducing several important features reported in HD patients such as progressive and sustained mitochondrial defects, detectable calpain activation and no major increase in caspase- 3 activity, we used this model to further examine the effects produced by calpain inhibition in vivo and its relevance to HD pathogenesis.

\section{CI-1 infusion inhibits calpain in vivo}

If calpain activity is central to striatal degeneration produced by sustained mitochondrial defects, inhibiting calpain could have 
A
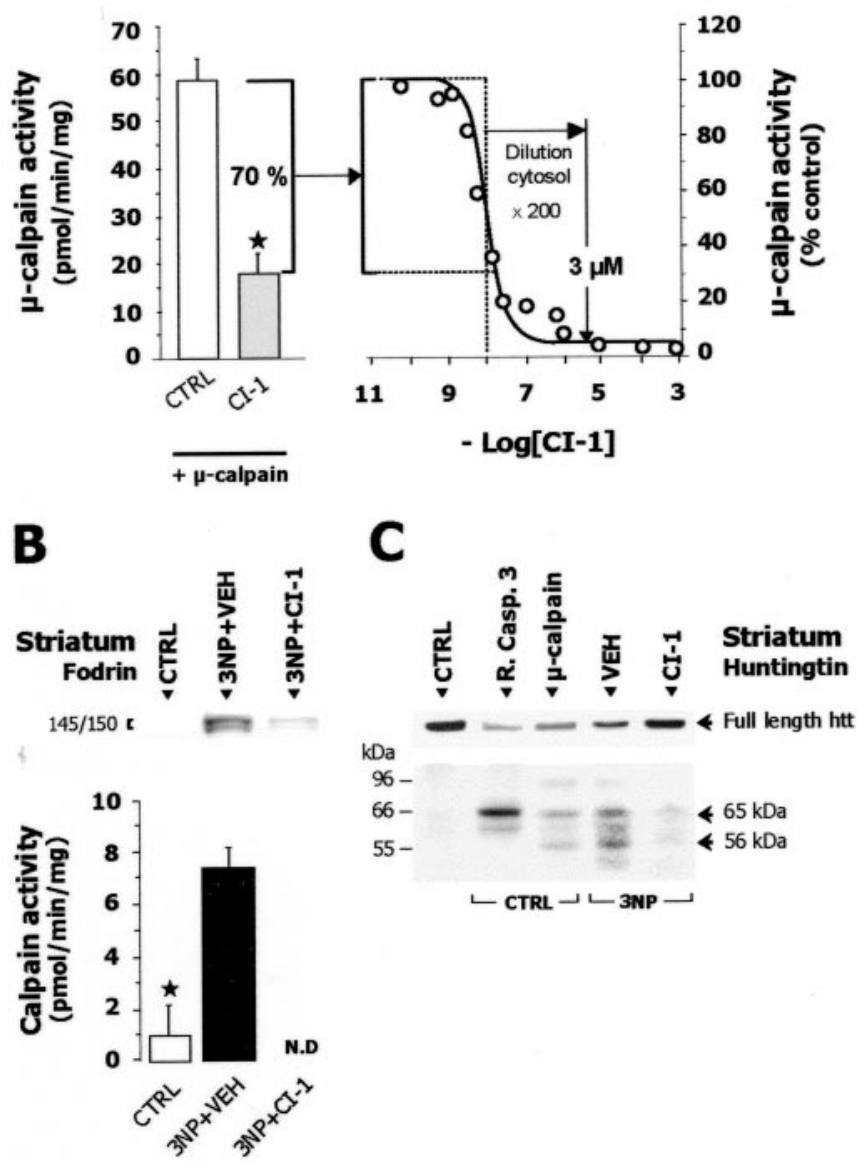

Figure 8. Calpain inhibitor $\mathrm{l}(\mathrm{Cl}-1)$ inhibits calpain in vitro and in vivo. $A$, Ex vivo estimation of the inhibiting effects of intracerebroventricular infusion of $\mathrm{Cl}-1(2.5 \mu \mathrm{g} / \mathrm{hr}$ for $5 \mathrm{~d})$ on calpain. Left panel, Striatal cytosol fractions from control (open bar) or 3-NP-treated rats infused with Cl-1 (gray bar) were incubated with purified $\mu$-calpain before measuring the enzyme activity in vitro. Right panel, Inhibition curve of purified $\mu$-calpain by $\mathrm{Cl}-1$ in vitro $\left(\mathrm{IC}_{50}=9.28 \mathrm{~nm}\right)$. $B$, Top panel, SDS PAGE followed by Western blot for fodrin in striatal membrane fraction prepared from chronic 3-NP-treated and CTRL rats. Note that Cl-1 compared with its vehicle (VEH) markedly inhibits in vivo the 3-NP-induced accumulation of the calpain-mediated 145/150 kDa breakdown products of fodrin. Bottom panel, Reduction of the activity of endogenous calpain by infusion of $\mathrm{Cl}-1$ in 3-NP-treated rats. C, SDS-PAGE followed by Western blot for huntingtin (Htt) of striatal samples from control (CTRL) or rats treated with 3-NP for $5 \mathrm{~d}$ (3-NP). Samples of CTRL rats were loaded after incubation with or without $\mu$-calpain or with or without caspase- 3 (R. Casp-3). 3-NP-treated rats received calpain inhibitor 1 (Cl-1) or its vehicle only (VEH). The 3-NP treatment induces a reduction of full-length $\mathrm{Htt}$ concentrations and the appearance of $\mathrm{Htt}$ breakdown products ( 56 and $65 \mathrm{kDa}$, arrows) which are similar to those observed after in vitro cleavage of control striatum samples by $\mu$-calpain. Note that in vivo treatment with $\mathrm{Cl}-1$ prevents the effects of 3-NP toxicity. N.D., Not detectable. $\star p<0.002$, Student's $t$ test.

neuroprotective effects. To test this hypothesis, we first examined whether intracerebroventricular infusion of the selective calpain inhibitor CI-1 would inhibit calpain in vivo. We first measured the inhibition of purified $\mu$-calpain induced by striatal soluble fractions taken from rats infused by CI- $1(2.5 \mu \mathrm{g} / \mathrm{hr}$ for $5 \mathrm{~d})$ or vehicle. Control samples produced no significant inhibition of purified $\mu$-calpain. In contrast, fractions from CI-1-treated animals significantly inhibited the activity of the purified enzyme by 70\% (Fig. 8A).

By measuring the in vitro $\mathrm{IC}_{50}$ value of $\mathrm{CI}-1$ for $\mu$-calpain $(9.28 \mathrm{nM})$ and taking into account the various dilution factors ( $\sim 200$-fold) resulting from striatum dissection, homogenization and the in vitro $\mu$-calpain assay, we estimated striatal concentra- tions of CI-1 inhibiting calpain in vivo at $\sim 3 \mu \mathrm{M}$ (Fig. $8 A$ ). We then examined whether this dose of CI-1 could effectively prevent the activation of calpain in vivo and the accumulation of calpaindependent $145 / 150 \mathrm{kDa}$ fodrin breakdown products. On day 5 of chronic 3-NP treatment, animals receiving CI-1 displayed a significant reduction in endogenous calpain activity and in calpaindependent fodrin breakdown products compared with control rats receiving the vehicle alone (Fig. $8 \mathrm{~B}$ ).

\section{Calpain inhibition prevents 3-NP-induced cleavage of huntingtin}

Since Htt is cleaved by caspases and calpains into fragments of different molecular weights (Kim et al., 2001), we used Western blot analysis to determine whether calpain activation modified the pattern of $\mathrm{Htt}$ processing observed in vivo during chronic 3-NP administration. Using an antibody directed against the $\mathrm{N}$-terminal part of the Htt protein, a major band of high molecular weight $(>300 \mathrm{kDa})$ corresponding to full-length Htt was detected in control striatal samples (Fig. 8C), whereas the intensity of this band was decreased at day 5 in the 3-NP-treated animals. Additionally, striatal samples from 3-NP-treated rats presented two main immunoreactive bands of $65 \mathrm{kDa}$ and $56 \mathrm{kDa}$, corresponding to breakdown products of Htt. Similar bands were found when control striatal samples were digested with $\mu$-calpain in vitro (Fig. $8 C$ ). Infusing calpain inhibitor CI-1 in the 3-NPtreated rats reduced both the decrease in full-length $\mathrm{Htt}$ and the accumulation of these two Htt breakdown products, indicating that abnormal cleavage of Htt was reduced by intracerebroventricular infusion of CI-1 in vivo.

Calpain inhibition prevents 3-NP-induced striatal cell death Because CI-1 could block calpain activation and reduce abnormal processing of the wild-type $\mathrm{Htt}$ in the chronic model, we next examined whether CI-1 infusion could prevent 3-NP-induced striatal neurodegeneration. We evaluated the effects of CI-1 at day 5 of the chronic 3-NP treatment, at a time of severe striatal degeneration (Dautry et al., 2000; Ouary et al., 2000; Garcia et al., 2002; Mittoux et al., 2002). CI-1 markedly reduced the size of striatal lesions and resulted in cytochrome oxidase levels (a marker of neuronal integrity) near control values (Fig. 9A-C). The Cl-1 effects were not caused by a direct interaction of $\mathrm{Cl}-1$ with 3-NP, because the SDH inhibition was similar in vehicle- or CI-1-treated rats (data not shown). In addition, we analyzed the effect of CI-1 on DNA fragmentation, a late stage marker of 3-NP-induced neurodegeneration. We showed that CI-1 prevented DNA fragmentation in striatal cells as detected by the levels of free oligonucleosomes and the number of TUNELpositive cells in the striatum (Fig. 9D-F).

\section{Discussion}

We used two different animal models of mitochondrial blockade associated either with transient or sustained complex II inhibition, and we found that whereas activation of calpain was observed in both conditions, this was not the case for another death effector protease, caspase-3. In addition, calpain activity was specifically increased in the striatum, a region known to be specifically sensitive to both 3-NP-induced degeneration and HD pathology but not in the cerebral cortex. Finally, calpain inhibition spared striatal cells from neurodegeneration. Together, these data indicate that calpain activation is essential in 3-NP-induced striatal cell death. Because a sustained and partial mitochondrial complex II defect has been reported so far in HD (Brouillet et al., 
A
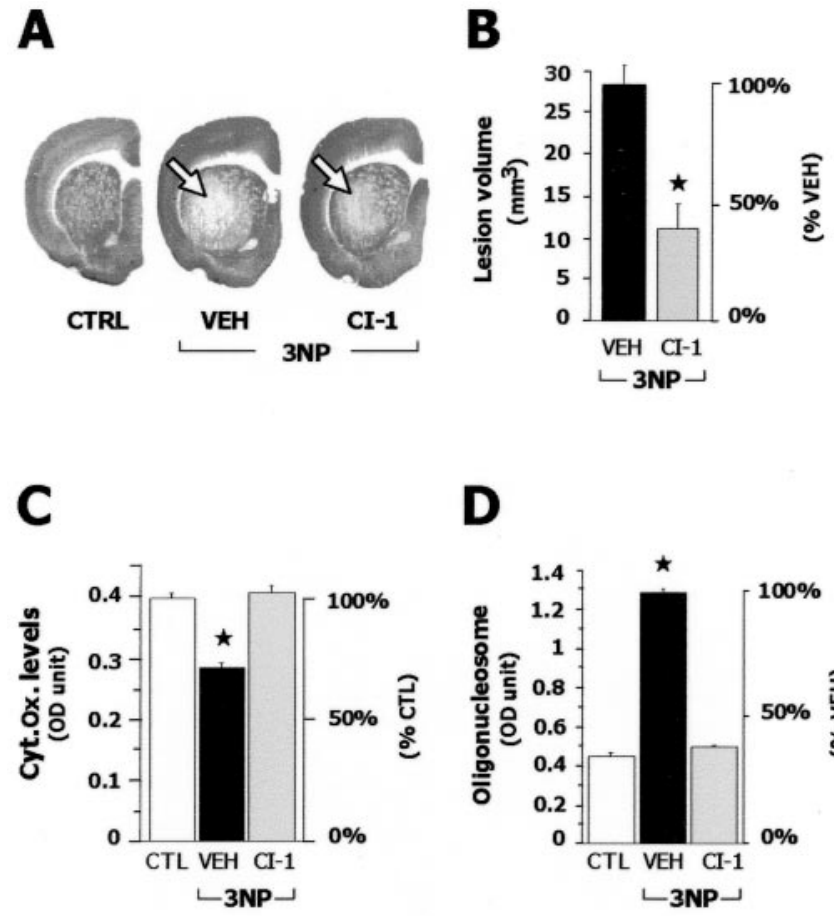

$\mathbf{E}$

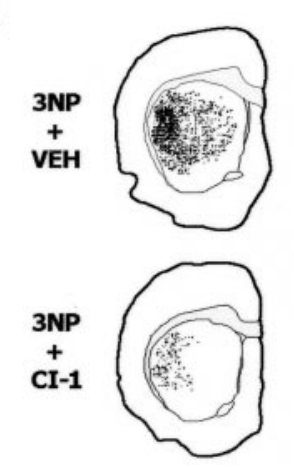

D

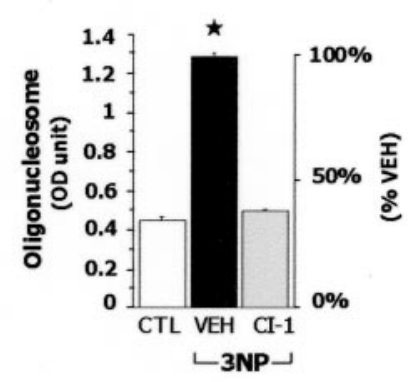

$\mathbf{F}$

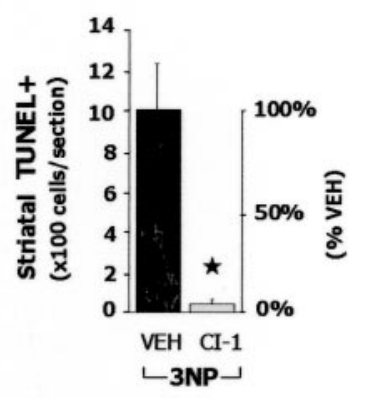

Figure 9. Calpain inhibition protects the striatum against chronic 3-NP toxicity. Control rats (CTRL) and rats treated for $5 \mathrm{~d}$ with 3-NP received continuous infusion of $\mathrm{Cl}-1$ or its vehicle (VEH). A, Representative coronal brain sections stained for cytochrome oxidase histochemistry: 3-NPtreated rats that received vehicle showed severe striatal neurodegeneration (open arrow), which is reduced by $\mathrm{Cl}-1$ treatment. B, Quantification of the 3-NP-induced striatal lesion volume. C, Quantification of cytochrome oxidase activity. D, ELISA quantification of oligonucleosomes (DNA fragmentation) in the cytosol prepared from the striatum of CTRL and 3-NP-treated rats with or without $\mathrm{Cl}-1$ treatment. $E$, Localization of striatal neurons with DNA fragmentation (TUNEL-positive cells) on coronal sections from 3-NP-treated rats. Section from the Cl-1-treated animal with the highest TUNEL-positive cell density is shown. F, Quantification of striatal TUNEL-positive neurons in 3-NP-treated animals. Data are means \pm SEM measured in six or seven animals. $\star p<0.005$, two groups comparison using unpaired Student's $t$ test $(B, F)$ or $p<0.002$ compared with CTRL using ANOVA and post hoc Scheffe $F$ test $(C, D)$.

1999), these data also strongly support a direct implication of calpain in HD pathogenesis.

Using a number of biochemical and immunocytochemical evidence, we have shown that caspase- $9,-8$, and -3 are all activated in the model of transient mitochondrial inhibition. In this situation, the activation of caspase- 3 may result from the cleavage of its zymogen form by upstream caspase- 9 and/or caspase- 8 , and this is consistent with our observations that upstream caspase- 8 and -9 activation precedes caspase- 3 activation in the striatum after acute 3-NP treatment. Although activation of caspase path-

ways is well known to occur in cell culture models of energy compromise (Du et al., 1997; Leist et al., 1998; Hartmann et al., 2000; Ohgoh et al., 2000; Newcomb-Fernandez et al., 2001), our data suggest that acute 3-NP toxicity in vivo may involve molecular actors of apoptosis as well. In agreement with our present findings, activation of caspase- 3 has been observed in vivo under experimental conditions associated with transient mitochondrial perturbation such as focal ischemia (Namura et al., 1998; Benchoua et al., 2001), intrastriatal injection of the 3-NP analog malonate (Schulz et al., 1998), or subacute repeated injections of 3-NP (Duan et al., 2000; Kim et al., 2000).

In clear contrast with the findings in the acute model, we found no activation of caspase-8 during chronic 3-NP treatment. Despite an activation of caspase- 9 , no caspase- 3 activation was detected. The reasons for this are unclear. One hypothesis is that the spreading out of apoptotic events in the chronic model evolving over $5 \mathrm{~d}$ would not have allowed us to detect caspase- 8 and -3 activation. Although we cannot completely rule out this possibility, the spreading out of apoptotic events would similarly impede detecting caspase- 9 activation in the chronically treated rats. A more likely explanation is that specific molecular events may preclude caspase- 3 activation and/or the accumulation of active forms of caspase- 3 in the chronic model. One possibility is that caspase- 9 activation leads to caspase- 3 processing but that the rate of degradation of the active forms of caspase- 3 is accelerated in this model, preventing the accumulation of functional forms of the death effector protease. In favor of this hypothesis, preliminary data obtained in vitro and in vivo using the chronic 3-NP model show that processed caspase- 3 can be degraded by calpain (N. Bizat, J.-M. Hermel, P. Hantraye, S. Krajewski, and E. Brouillet, unpublished observations). Additional studies will be needed to understand the absence of processed forms of caspase- 3 in the chronic 3-NP model.

Regardless of the precise mechanisms of caspase- 3 regulation, our data demonstrate that one mitochondrial toxin may activate different cell death mechanisms, depending on the pattern of acute and chronic mitochondrial perturbation. Our data also suggest that increased caspase- 3 processing may not be strictly required for 3-NP to produce striatal degeneration. This absence of "pathological" caspase- 3 processing in the chronic model is reminiscent of the absence of abnormal caspase- 3 processing observed in HD patients and in transgenic mice models overexpressing the full-length Htt protein. In line with this, whereas neurotoxicity of quinolinate in wild-type rodents in vivo seems to require caspase-3 processing (Qin et al., 2000), quinolinate toxicity in transgenic YAC72 mice overexpressing a full-length mutated $\mathrm{Htt}$ is not associated with an increased caspase-3-mediated cleavage of Htt (Zeron et al., 2002). However, the toxicity of the mutated Htt requires the presence of caspases (Saudou et al., 1998; Sanchez et al., 1999), probably for cleavage of full-length $\mathrm{Htt}$ into shorter and more toxic fragments (Wellington et al., 2002). In a number of physiological forms of cell death, increased processing of effector caspases, especially caspase- 3 is observed (Nicholson and Thornberry, 1997). For Htt toxicity in HD, the role of caspase pathways may not necessarily be associated with increased caspase processing. The results from the chronic 3-NP model suggest that the striatal cell death resulting from mitochondrial defects in HD patients may not require abnormal caspase activation and that other death effector proteases are implicated in the disease process.

A novel finding of the present work is that the cysteine protease calpain is the essential cell death effector in 3-NP-induced HD-like pathogenesis. In the mammalian brain, calpains ( $\mu$ - 
calpain and m-calpain) are present as heterodimers (catalytic 80 $\mathrm{kDa}$ subunit and regulatory $30 \mathrm{kDa}$ subunit) in the cytosol and are activated by increases in $\mathrm{Ca}^{2+}$ concentrations (Chan and Mattson, 1999; Wang, 2000). In the present study, calpain activity was increased by 3-NP in conditions of both transient and sustained inhibition of the respiratory chain. Results from Western blot analysis suggest that in the chronic 3-NP model this activation involves $\mu$-calpain. It has been shown that once activated by micromolar concentrations of $\mathrm{Ca}^{2+}, \mu$-calpain can itself activate $\mathrm{m}$-calpain through a "heterolytic" processing (Tompa et al., 1996). Thus, it is likely that m-calpain is also activated by $3-\mathrm{NP}$, although additional studies are required to precisely examine this point. Additionally, we demonstrated a calpain-dependent decrease in full-length $\mathrm{Htt}$, coincident with the appearance of $\mathrm{Htt}$ breakdown products in the striatum of 3-NP-treated rats. Finally, the present data show that calpain activation in vivo likely plays a central role in 3-NP toxicity because pharmacological inhibition of the protease produces significant neuroprotective effects against neurotoxin effects.

The mechanisms underlying the "pathological" activation of calpain in 3-NP-treated animals remain speculative but probably involve alterations in $\mathrm{Ca}^{2+}$ homeostasis. Although we show that 3-NP produces a partial blockade of SDH/complex II in our models, further studies will be necessary to characterize in vivo the early consequences of this blockade on mitochondrial membrane potential, radical oxygen species production, $\mathrm{Ca}^{2+}$ uptake capacity, oxidative phosphorylation, and general cellular energy charge. However, it is likely that ATP concentrations are not profoundly modified in the 3-NP models at time points preceding overt tissue damage because (1) we observed caspase- 9 activation, which is an ATP-dependent process, and (2) we previously showed increased phosphorylation of the c-jun N-terminal kinase in the chronic model (Garcia et al., 2002). One interesting hypothesis is that the 3-NP-induced partial blockade of SDH may reduce the capacity of mitochondria to regulate cytosolic $\mathrm{Ca}^{2+}$ concentrations. Interestingly, $\mathrm{Ca}^{2+}$ entering through NMDA receptors is tightly regulated by mitochondrial reuptake system in neurons (Peng and Greenamyre, 1998). Thus, it is possible that once SDH is partially inhibited by $3-\mathrm{NP}$, the pool of cytosolic $\mathrm{Ca}^{2+}$ associated with physiological NMDA receptor activation may be inefficiently regulated by mitochondria leading to a rise in cytosolic $\mathrm{Ca}^{2+}$ concentrations. As shown previously in brain slices and neurons in culture, at concentrations that do not increase cytosolic $\mathrm{Ca}^{2+}$ per se, 3-NP markedly potentiates the rise in $\mathrm{Ca}^{2+}$ produced by NMDA receptor stimulation in striatal medium-size spiny neurons (Greene et al., 1998; Calabresi et al., 2001). Several studies in cell culture or in rats also support an important role of NMDA receptors in 3-NP toxicity (Beal et al., 1993; Simpson and Isacson, 1993; Wüllner et al., 1994; Zeevalk et al., 1995). However, it cannot be ruled out that 3-NP produces at least in part, $\mathrm{Ca}^{2+}$ changes independently of NMDA receptors. Other pools of $\mathrm{Ca}^{2+}$ may be also affected such as the pool of the endoplasmic reticulum. An excess of intracellular $\mathrm{Ca}^{2+}$ could activate calpain, leading to cleavage of specific substrates important for cell survival, and eventually cell death.

The presence of activated calpain in the striatum of rats with chronic mitochondrial deficits is highly reminiscent of the modifications observed recently in HD patients (Gafni and Ellerby, 2002). HD patients have an increase in the activated calpain, as revealed by the presence of cleaved $30 \mathrm{kDa}$ regulatory subunit on Western blot and upregulation of $\mu$ - and m-calpain in the caudate nucleus as seen by immunohistochemistry. In addition, the calpain-dependent cleavage of Htt is increased in the caudate of HD patients (Kim et al., 2001; Gafni and Ellerby, 2002). Our results showing that $3-\mathrm{NP}$ can indirectly activate calpain in vivo are, to our knowledge, the first demonstration that calpain abnormalities in HD could directly result from the chronic mitochondrial defects that have been consistently observed in HD patients (Jenkins et al., 1993, 1998; Gu et al., 1996; Browne et al., 1997; Sawa et al., 1999; Tabrizi et al., 1999; Panov et al., 2002). The present results also demonstrate that calpain activation is region-selective, which could explain the preferential vulnerability of the striatum for 3-NP-induced chronic mitochondrial inhibition. Whereas systemic 3-NP administration produces an ubiquitous inhibition of SDH activity in the brain (Brouillet et al., 1998; Garcia et al., 2002), calpain activation was only observed in the striatum and not in other brain regions, less vulnerable to the neurotoxin such as the cerebral cortex. One possibility for explaining a region-specific activation of calpain is that for a similar level of 3-NP-induced SDH inhibition, changes in intracellular $\mathrm{Ca}^{2+}$ concentrations are higher within striatal projection neurons compared with less vulnerable cells, such as cortical neurons. Alternatively, 3-NP may increase $\mathrm{Ca}^{2+}$ in many brain regions, whereas calpain in striatal neurons may be particularly susceptible to activation by $\mathrm{Ca}^{2+}$. Possible contributing factors to such a susceptibility might include regional differences in substrates and inhibitors and/or regulation of expression of the protease. Whether such a striatal-selective activation of calpain also occurs in HD awaits further study.

The results of the chronic 3-NP model also suggest the existence of a vicious circle in which mitochondrial defects in HD could amplify the toxic effects of mutated Htt. Mitochondrial defects resulting from Htt mutation may lead to anomalies in $\mathrm{Ca}^{2+}$ homeostasis (possibly at the level of pools of $\mathrm{Ca}^{2+}$ associated with NMDA receptors) and "uncontrolled" calpain activation. This would in turn increase cleavage of full length Htt. Given that wild-type $\mathrm{Htt}$ is neuroprotective against mutated $\mathrm{Htt}$ (Cattaneo et al., 2001), this would render striatal cells more vulnerable to mutated Htt. In addition, the increased calpainmediated cleavage of mutated Htt may generate shorter $\mathrm{N}$ terminus fragments containing the toxic polyglutamine stretch. Because it has been shown that for a given polyglutamine length (higher than 37), the shorter the fragment, the higher the toxicity (Hackam et al., 1998), the activation of calpain would amplify the toxic effects of mutated Htt. Finally, in addition to the amplification of Htt toxicity, high levels of activated calpain may directly lead to cell death through proteolysis of other calpain-sensitive neuronal proteins.

It is possible that the mitochondrial perturbation-induced calpain activation may be also involved in other neurodegenerative disorders such as Alzheimer's disease (Chan and Mattson, 1999; Lee et al., 2000), which has been associated with secondary mitochondrial defects (Beal, 2000). In this context, it has been hypothesized that calpain blockade in neurodegenerative diseases may be of therapeutic interest (Di Rosa et al., 2002). Supporting this view, we demonstrate that calpain blockade produces a significant neuroprotection including drastic reduction of DNA fragmentation in the chronic 3-NP model of HD.

In conclusion, the present study points to calpain as one of the major actors of cell death process in HD and strongly supports the hypothesis that inhibiting calpain activity is a potential therapeutic strategy for the treatment of HD and possibly other neurodegenerative disorders. 


\section{References}

Albin RL, Greenamyre JT (1992) Alternative excitotoxic hypotheses. Neurology 42:733-738.

Beal MF (1992) Does impairment of energy metabolism result in excitotoxic neuronal death in neurodegenerative illness? Ann Neurol $31: 119-130$.

Beal MF (2000) Energetics in the pathogenesis of neurodegenerative disorders. Trends Neurosci 7:298-304.

Beal MF, Brouillet E, Jenkins B, Ferrante R, Kowall N, Miller J, Storey E, Srivastava R, Rosen B, Hyman BT (1993) Neurochemical and histologic characterization of the striatal lesions produced by the mitochondrial toxin 3-nitropropionic acid. J Neurosci 13:4181-4192.

Benchoua A, Guegan C, Couriaud C, Hosseini H, Sampaio N, Morin D, Onteniente B (2001) Specific caspase pathways are activated in the two stages of cerebral infarction. J Neurosci 21:7127-7134.

Blum D, Gall D, Galas MC, d'Alcantara P, Bantubungi K, Schiffmann SN (2002) The adenosine Al receptor agonist ADAC exerts a neuroprotective effect against the development of striatal lesions and motor impairments in the 3-nitropropionic acid of neurotoxicity. J Neurosci 22:9122-9133.

Brouillet E, Guyot M-C, Mittoux V, Altairac S, Condé F, Palfi S, Hantraye P (1998) Partial inhibition of brain succinate dehydrogenase by 3-nitropropionic acid is sufficient to initiate striatal degeneration in Rat. J Neurochem 70:794-805.

Brouillet E, Condé F, Beal MF, Hantraye P (1999) Replicating Huntington's disease in experimental animals. Prog Neurobiol 59:427-458.

Browne SE, Bowling AC, Mac Garvey U, Baik MJ, Berger SC, Muqit MK, Bird ED, Beal MF (1997) Oxidative damage and metabolic dysfunction in Huntington's disease: selective vulnerability of the basal ganglia. Ann Neurol 41:646-653.

Calabresi P, Gubellini P, Picconi B, Centonze D, Pisani A, Bonsi P, Greengard P, Hipskind RA, Borrelli E, Bernardi G (2001) Inhibition of mitochondrial complex II induces a long-term potentiation of NMDA-mediated synaptic excitation in the striatum requiring endogenous dopamine. J Neurosci 21:5110-5120.

Cattaneo E, Rigamonti D, Goffredo D, Zuccato C, Squitieri F, Sipione S (2001) Loss of normal huntingtin function: new developments in Huntington's disease research. Trends Neurosci 24:182-188.

Cepeda C, Ariano MA, Calvert CR, Flores-Hernandez J, Chandler SH, Leavitt BR, Hayden MR, Levine MS (2001) NMDA receptor function in mouse models of Huntington disease. J Neurosci Res 66:525-539.

Chan SL, Mattson MP (1999) Caspase and calpain substrates: roles in synaptic plasticity and cell death. J Neurosci Res 58:167-190.

Dautry C, Vauffrey F, Brouillet E, Bizat N, Condé F, Bloch G, Hantraye P (2000) Early $N$-acetylaspartate depletion is a marker of neuronal dysfunction in rats and primates chronically treated with the mitochondrial toxin 3-nitropropionic acid. J Cereb Blood Flow Metab 20:789-799.

DiFiglia M (1990) Excitotoxic injury of the neostriatum: a model for Huntington's disease. Trends Neurosci 13:286-289.

Di Rosa G, Odrijin T, Nixon RA, Arancio O (2002) Calpain inhibitors: a treatment for Alzheimer's disease. J Mol Neurosci 19:135-141.

Du Y, Dodel RC, Bales KR, Jemmerson R, Hamilton-Byrd E, Paul SM (1997) Involvement of a caspase-3-like cysteine protease in 1-methyl-4phenylpyridinium-mediated apoptosis of cultured cerebellar granule neurons. J Neurochem 69:1382-1388.

Duan W, Zhiong G, Mattson M (2000) Participation of Par-4 in the degeneration of striatal neurons induced by metabolic compromise with 3-nitropropionic acid. Exp Neurol 165:1-11.

Gafni J, Ellerby LM (2002) Calpain activation in Huntington's disease. J Neurosci 22:4842-4849.

Garcia M, Vanhoutte P, Pages C, Besson MJ, Brouillet E, Caboche J (2002) Activation of the c-Jun-N-terminal kinase/c-Jun module occurs in striatal neurons in response to 3-nitropropionic acid: a comparative in vivo and in vitro analysis. J Neurosci 22:2174-2184.

Greene JG, Greenamyre JT (1995) Characterization of the excitotoxic potential of the reversible succinate dehydrogenase inhibitor malonate. J Neurochem 64:430-436.

Greene JG, Sheu S-S, Gross RA, Greenamyre JT (1998) 3-nitropropionic acid exacerbates $N$-methyl-D-aspartate toxicity in striatal culture by multiple mechanisms. Neuroscience 84:503-510.

Gu M, Gash MT, Mann VM, Javoy-Agid F, Cooper JM, Shapira AH (1996)
Mitochondrial defect in Huntington's disease caudate nucleus. Ann Neurol 39:385-389.

Hackam AS, Singaraja R, Wellington CL, Metzler M, McCutcheon K, Zhang T, Kalchman M, Hayden MR (1998) The influence of huntingtin protein size on nuclear localization and cellular toxicity. J Cell Biol 141:1097-1105.

Harper PS (1991) Huntington's disease (Harper PS, ed). London: Saunders. Hartmann A, Hunot S, Michel PP, Muriel MP, Vyas S, Faucheux BA, MouattPrigent A, Turmel H, Srinivasan A, Ruberg M, Evan GI, Agid Y, Hirsch EC (2000) Caspase-3: a vulnerability factor and final effector in apoptotic death of dopaminergic neurons in Parkinson's disease. Proc Natl Acad Sci USA 97:2875-2880.

Hermel J-M, Dirkx R, Solimena M (1999) Post-translational modifications of ICA512 a receptor tyrosine phosphatase-like protein of secretory granules. Eur J Neurosci 11:2609-2620.

Huntington's Disease Collaborative Research Group (1993) A novel gene containing a trinucleotide repeat that is expanded and unstable on Huntington's disease chromosomes. Cell 72:971-983.

Jenkins BG, Koroshetz WJ, Beal MF, Rosen R (1993) Evidence for an energy metabolic defect in Huntington's Disease using localized proton spectroscopy. Neurology 43:2689-2693.

Jenkins BG, Rosas HD, Chen YCI, Makabe T, Myers R, MacDonald M, Rosen BR, Beal MF, Koroshetz WJ (1998) 1H NMR spectroscopy studies of Huntington's Disease correlation with CAG repeat numbers. Neurology 50:1357-1365.

Kim GW, Copin JC, Kawase M, Chen SF, Sato S, Gobbel GT, Chan PH (2000) Excitotoxicity is required for induction of oxidative stress and apoptosis in mouse striatum by the mitochondrial toxin 3-nitropropionic acid. J Cereb Blood Flow Metab 20:119-129.

Kim YJ, Yi Y, Sapp E, Wang Y, Cuiffo B, Kegel KB, Qin ZH, Aronin N, DiFiglia M (2001) Caspase-3-cleaved N-terminal fragments of wild-type and mutant huntingtin are present in normal and Huntington's disease brains associate with membranes and undergo calpain-dependent proteolysis. Proc Natl Acad Sci USA 98:12784-12789.

Krajewski S, Krajewska M, Ellerby LM, Welsh K, Xie Z, Deveraux QL, Salvesen GS, Bredesen DE, Rosenthal RE, Fiskum G, Reed JC (1999) Release of caspase-9 from mitochondria during neuronal apoptosis and cerebral ischemia. Proc Natl Acad Sci USA 96:5752-5757.

Laforet GA, Sapp E, Chase K, McIntyre C, Boyce FM, Campbell M, Cadigan BA, Warzecki L, Tagle DA, Reddy PH, Cepeda C, Calvert CR, Jokel ES, Klapstein GJ, Ariano MA, Levine MS, DiFiglia M, Aronin N (2001) Changes in cortical and striatal neurons predict behavioral and electrophysiological abnormalities in a transgenic murine model of Huntington's disease. J Neurosci 21:9112-9123.

Lee M-S, Kwon YT, Li M, Peng J, Friedlander RM, Tsai LH (2000) Neurotoxicity induces cleavage of p35 to p25 by calpain. Nature 405:360-364.

Leist M, Volbracht C, Fava E, Nicotera P (1998) 1-Methyl-4-phenylpy ridinium induces autocrine excitotoxicity protease activation and neuronal apoptosis. Mol Pharmacol 54:789-801.

McDonald MC, Mota-Filipe H, Paul A, Cuzzocrea S, Adbelrahman M, Harwood S, Plevin R, Chatterje PK, Yaqoob MM, Thiemermann C (2001) Calpain inhibitor I reduces the activation of nuclear factor-kappaB and organ injury/dysfunction in hemorrhagic shock. FASEB 15:171-186.

Mittoux V, Ouary S, Monville C, Lisovoski F, Poyot T, Conde F, Escartin C, Robichon R, Brouillet E, Peschanski M, Hantraye P (2002) Corticostriatopallidal neuroprotection by adenovirus-mediated ciliary neurotrophic factor gene transfer in a rat model of progressive striatal degeneration. J Neurosci 22:4478-4486.

Namura S, Zhu J, Fink K, Endres M, Srinivasan A, Tomaselli KJ, Yuan J, Moskowitz MA (1998) Activation and cleavage of caspase-3 in apoptosis induced by experimental cerebral ischemia. J Neurosci 18:3659-3668.

Newcomb-Fernandez JK, Zhao X, Pike BR, Wang KK, Kampfl A, Beer R, DeFord SM, Hayes RL (2001) Concurrent assessment of calpain and caspase-3 activation after oxygen-glucose deprivation in primary septohippocampal cultures. J Cereb Blood Flow Metab 21:1281-1294.

Nicholson DW, Thornberry NA (1997) Caspases: killer proteases. Trends Biochem Sci 22:299-306.

Ohgoh M, Shimizu H, Ogura H, Nishizawa Y (2000) Astroglial trophic support and neuronal cell death: Influence of cellular energy level on type of cell death influenced by mitochondrial toxin in cultured rat cortical neurons. J Neurochem 75:925-933. 
Ouary S, Bizat N, Altérac S, Ménétrat H, Mittoux V, Condé F, Hantraye P, Brouillet E (2000) Major strain differences in response to chronic systemic administration of the mitochondrial toxin 3-nitropropionate in rats: implications for neuroprotection studies. Neurosci 97:521-530.

Panov AV, Gutekunst CA, Leavitt BR, Hayden MR, Burke JR, Strittmatter WJ, Greenamyre JT (2002) Early mitochondrial calcium defects in Huntington's disease are a direct effect of polyglutamines. Nat Neurosci 5:731-736.

Peng TI, Greenamyre JT (1998) Privileged access to mitochondria of calcium influx through $N$-methyl-D-aspartate receptors. Mol Pharmacol 53:974-980.

Petersen A, Mani K, Brundin P (1999) Recent advances on the pathogenesis of Huntington's disease. Exp Neurol 157:1-18.

Qin Z, Wang Y, Chasea TN (2000) A caspase-3-like protease is involved in NF-kappaB activation induced by stimulation of $N$-methyl-D-aspartate receptors in rat striatum. Brain Res Mol Brain Res 80:111-122.

Sanchez I, Xu CJ, Juo P, Kakizaka A, Blenis J, Yuan J (1999) Caspase-8 is required for cell death induced by expanded polyglutamine repeats. Neuron 22:623-633.

Saudou F, Finkbeiner S, Devys D, Greenberg M (1998) Huntingtin acts in the nucleus to induce apoptosis but death does not correlate with the formation of intranuclear inclusions. Cell 95:55-66.

Sawa A, Wiegand GW, Cooper J, Margolis R, Sharp AH, Lawler JF, Greenamyre JT, Snyder SH, Ross C (1999) Increased apoptosis of Huntington disease lymphoblasts associated with repeat length-dependent mitochondrial depolarization. Nat Med 5:1194-1198.

Schulz JB, Weller M, Matthews RT, Heneka MT, Groscurth P, Martinou JC, Lommatzsch J, Coelin RV, Wulner U, Loschmann PA, Beal MF, Dichgans J, Klockgether T (1998) Extended therapeutic window for caspase inhibition and synergy with MK-801 in the treatment of cerebral histotoxic hypoxia. Cell Death Differ 5:847-857.
Simpson JR, Isacson O (1993) Mitochondrial impairment reduces the threshold for in vivo NMDA-mediated neuronal death in the striatum. Exp Neurol 121:57-64.

Stoka V, Turk B, Schendel S, Cirman T, Snipas SJ, Ellerby L, Bredesen D, Freeze H, Abrahamson M, Broemme D, Krajewski S, Reed JC, Yin X-M, Turk V, Salvesen G (2001) Lysosomal protease pathways to apoptosis: cleavage of BID, not pro-caspases, is the most likely route. J Biol Chem 276:3149-3157.

Tabrizi SJ, Cleeter MW, Xuereb J, Taanman J-W, Cooper JM, Shapira AHV (1999) Biochemical abnormalities and excitotoxicity in Huntington's disease brain. Ann Neurol 45:25-32.

Tompa P, Baki A, Schad E, Friedrich P (1996) The calpain cascade. Mucalpain activates m-calpain. J Biol Chem 271:33161-33164.

Wang K (2000) Calpain and caspase: can you tell the difference? Trends Neurosci 23:20-26.

Wellington CL, Ellerby LM, Gutekunst CA, Rogers D, Warby S, Graham RK, Loubser O, van Raamsdonk J, Singaraja R, Yang YZ, Gafni J, Bredesen D, Hersch SM, Leavitt BR, Roy S, Nicholson DW, Hayden MR (2002) Caspase cleavage of mutant huntingtin precedes neurodegeneration in Huntington's disease. J Neurosci 22:7862-7872.

Wüllner U, Young A, Penney J, Beal MF (1994) 3-nitropropionic acid toxicity in the striatum. J Neurochem 63:1772-1781.

Zeevalk GD, Derr-Yellin E, Nicklas WJ (1995) Relative vulnerability of dopamine and GABA neurons in mesencephalic culture to inhibition of succinate dehydrogenase by malonate and 3-nitropropionic acid and protection by NMDA receptor blockade. J Pharmacol Exp Ther 275:1124-1130.

Zeron MM, Hansson O, Chen N, Wellington CL, Leavitt BR, Brundin P, Hayden MR, Raymond LA (2002) Increased sensitivity to $N$-methyl-Daspartate receptor-mediated excitotoxicity in a mouse model of Huntington's disease. Neuron 33:849-860. 